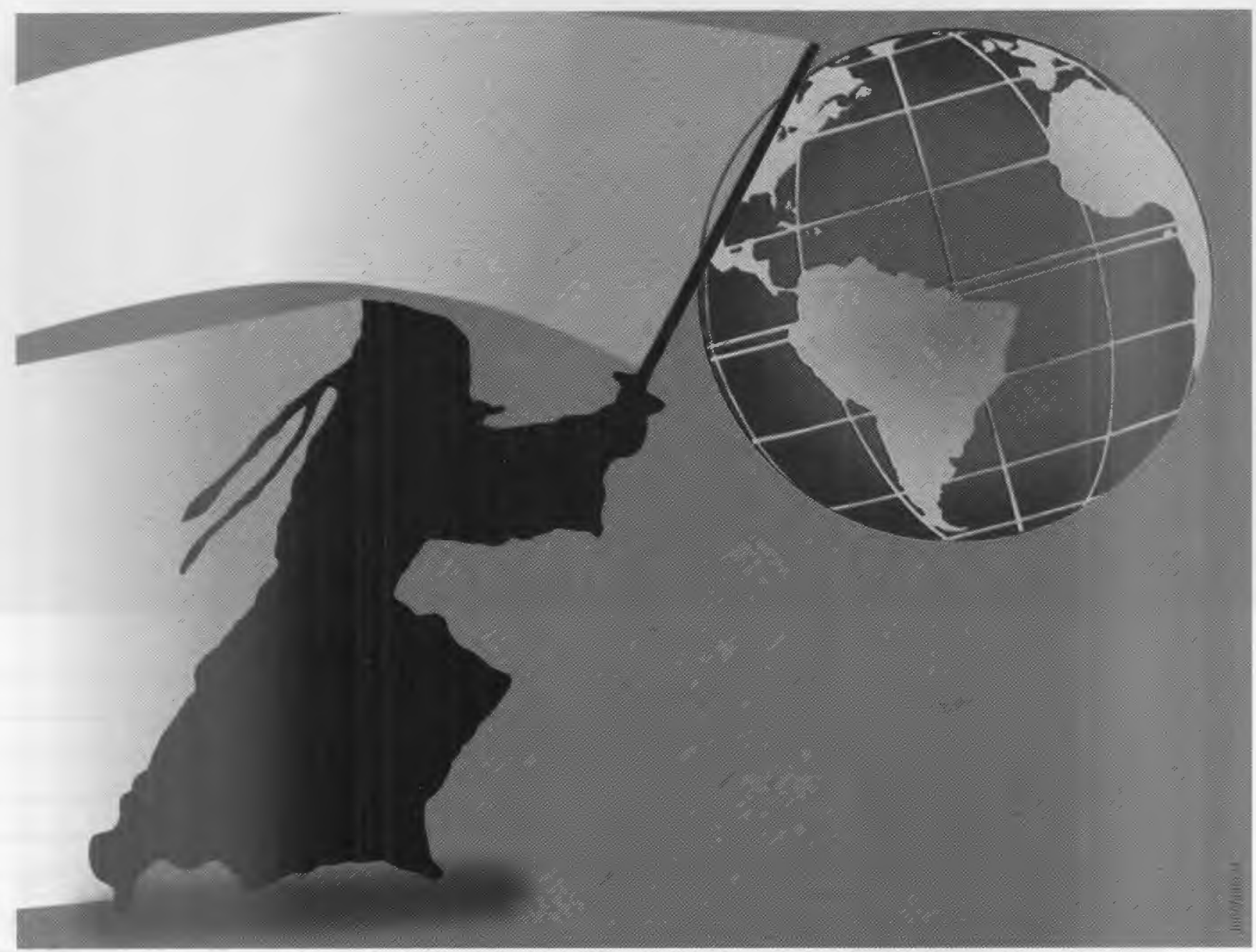

\title{
ESTRATÉGIAS PARA COMPETITIVIDADE NA PRODUÇÃO: O ENFOQUE DO LESTE ASIÁTICO
}

Mitsuhiro Kagami

Professor Visitante, Banco Interamericano de

Desenvolvimento. Washington D.C.

Tradução de Maria Inês Barreto, revista pelo Professor José Luiz Celeste, Professor do Departamento de Informática e Métodos Quantitativos da EAESP/FGV.

* RESUMO: Neste artigo, o autor apresenta as especificidades da cultura Leste Asiática e, em especial, do estilo japonês de gestão da produção. Quatro aspectos são examinados: as medidas internas à empresa, destinadas a aumentar a qualidade $e$ a produtividade, os relacionamentos interfirmas envolvendo considerações de custos entre verticalização externa e integração interna ou horizontal, a promoção das pequenas e médias empresas, enfatizando as medidas relativas às politicas de apoio às mesmas e, por fim, as orientações políticas, sumarizando sugestões para os países em desenvolvimento.
* PALAVRAS-CHAVE: Gestão estratégica, sistemas de produção, políticas públicas, pequenas e médias empresas, qualidade e competitividade.

* ABSTRACT: Peculiarities of East Asian culture focusing on the Japanese style of production management are tackled. Issues as in-house measures to increase productivity and quality, inter-firm relationships, cost aspects of internal/external verticalization and horizontal integration, leverage of small/medium scale firms through policies of base themselves are followed by policy directions for developing countries.

* KEY WORDS: Strategic management, production systems, policies, small and medium scale enterprises, quality and competitiveness.

São Paulo, 33(5):10-31 


\section{INTRODUÇÃO}

O principal tema a ser abordado neste trabalho é como aumentar a produtividade e a competitividade no setor manufatureiro, particularmente num momento em que mudanças drásticas ocorrem, em. função de medidas de liberalização do comércio e de uma maior abertura das economias. Dois fatores são cruciais em relação à produtividade e à competitividade: as medidas internas à empresa e os aspectos organizacionais.

As medidas internas à empresa incluem aperfeiçoamentos na escolha das matérias-primas, máquinas e equipamentos, na produçāo e processamento de tecnologia, no desenho industrial, na qualidade do produto e do trabalho e nos métodos gerenciais, aqui entendidos como relacionamentos que se estabelecem entre administradores e trabalhadores, bem como entre os trabalhadores entre si.

Os fatores organizacionais abrangem a divisão do trabalho intrafirmas, interfirmas e interindústrias, especialmente no que se refere às articulações operacionais entre os produtores de partes e componentes e as montadoras ou produtores finais, ou seja, o sistema de subcontrataçōes.

As empresas de grande porte tendem a integrar verticalmente o seu processo de produção, no âmbito de suas próprias fábricas, em razão da carência de fornecedores confiáveis de partes e de componentes. Entretanto, a experiência Leste Asiática demonstra que a integração vertical excessiva no sentido down stream $^{1}$ não é adequada, em termos de custo e de eficiência. Se os produtores de partes e de componentes ${ }^{2}$ surgiram separadamente, e se as suas articulações interfirmas bem como sua respectiva rede intersetorial - tiverem sido fortemente conectadas, os empresários serão capazes de reduzir o custo de transação, bem como os riscos que permeiam a indústria como um todo. As montadoras, em particular, desfrutam da competitividade de produtos de alta qualidade compostos de milhares de partes e de componentes fornecidos por produtores especializados. À medida que se estabelecem relações duradouras em um determinado agrupamento industrial, as informações acumu- lam-se, e as redes de informação que se desenvolvem, como resultado, ajudam a reduzir o tempo de projeto, assim como o custo de produção. Ao mesmo tempo, as empresas de suporte passam a gozar de uma estrutura de vendas estável, sustentada por pedidos de longa duração, feitos por produtores de bens finais. Em outras palavras, tanto montadoras quanto empresas de suporte compartilham as vantagens propiciadas pela quasi-rent ${ }^{3}$ e pe-

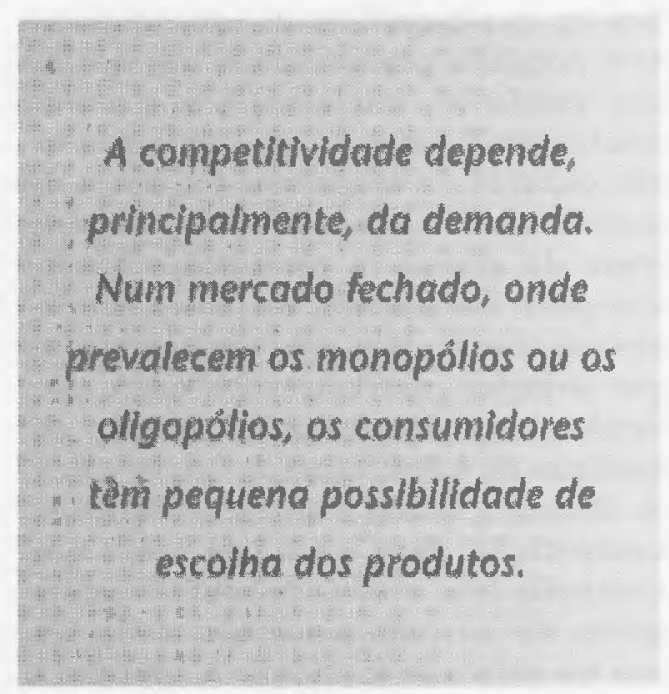

las informaçōes geradas entre os participantes, a longo prazo. Desta forma, é vital desenvolver pequenas e médias empresas de um estrato up and middlestream $^{4}$, ou seja, situadas nos estágios inicial e intermediário da cadeia produtiva, e integrá-las às empresas de tipo downstream. Este sistema de agrupamento ou subcontratação é um fator crucial para a competitividade.

Introduz-se, aqui, a cultura Leste Asiática, e, em especial, o estilo japonês de gestão da produção. A primeira parte deste artigo trata das medidas internas à empresa, destinadas a aumentar a produtividade e a qualidade. São também examinados os aspectos concernentes às iniciativas relativas à força de trabalho e à cooperação para aperfeiçoar a eficiência geral da produção. $\mathrm{Na}$ segunda parte é realizada uma comparaçāo, envolvendo considerações de custos, entre verticalização interna e integração externa ou horizontal. Um aspecto-chave das cadeias de suprimento é a existência de empresas confiáveis de pequeno e médio portes. A
1. N.T.: 0 autor utiliza a expressã̃o down stream firms ao referir-se às empresas que se seguem na cadeia produtiva.

2. Algumas vezes citados como "indústrias de suporte", uma vez que sustentam as montadoras, suprindo-as com seus produtos.

3. N. R.: vantagens semelhantes a um benefício monetário.

4. N.T.: tratam-se de empresas situadas nos estágios inicial e intermediário da cadeia produtlva, respectivamente. 
promoção destas empresas, no Japão, é explicada na terceira parte, enfatizandose as medidas relativas às políticas de suporte. Finalmente, a quarta parte sumariza as sugestões feitas para os países em desenvolvimento.

\section{AS MEDIDAS INTERNAS À EMPRESA}

A competitividade depende, principalmente, da demanda. Num mercado fechado, onde prevalecem os monopólios ou os oligopólios, os consumidores têm pequena possibilidade de escolha dos produtos. Entretanto, se existem muitos produtores, os consumidores serão capazes de selecionar produtos de acordo com as suas preferências. Num mercado aberto, os produtores devem competir. Geralmente, os países em desenvolvimento têm sido caracterizados por sistemas econômicos fechados, particularmente aqueles que adotaram estratégias de substituição de importações. A abertura dessas economias significa competição. Seus produtos terão que competir com outros produtos estrangeiros no mercado doméstico, assim como no mercado mundial. A questão é como aperfeiçoar produtos, no que diz respeito a preço, qualidade e serviços. As medidas internas à empresa afetam estes fatores, particularmente na indústria manufatureira.

Primeiramente, dois tipos de métodos de produção relacionados com a gestão dos recursos humanos e organizacionais são encontrados nas estruturas fabris: $o$ Método Ocidental (MO) e o Método do Extremo Oriente (MEO). O MO tem suas raízes no método de produção em massa de Ford e Taylor, no qual a divisão do trabalho é claramente definida por descrições específicas de trabalho; os trabalhadores têm responsabilidade restrita às suas respectivas áreas, definidas antecipadamente. $O \mathrm{MEO}$, que se origina no método Toyoda-Ohno de produção, é uma versão revisada do $\mathrm{MO}$, na qual a divisão de trabalho é intrincada. Os trabalhadores não são especializados numa atividade estreitamente definida, mas trabalham em equipe.

O MO é muito eficiente e adequado para processos estáticos de produção em massa; entretanto, quando um erro ocor- re, é também reproduzido em massa. Isto decorre do fato de que a produção em série não pode ser parada, mesmo quando o produto contém defeitos. Os trabalhadores da linha de montagem não têm poder para parar a linha; a responsabilidade usualmente recai sobre o gerente sênior da linha. Além disso, as atividades de inspeção e de descoberta de defeitos são ainda hoje de responsabilidade de uma outra pessoa. Os trabalhadores não são encorajados a se intrometer no território de terceiros. Em contraste, no MEO, os trabalhadores não apenas conhecem suas próprias funções, mas também as relativas a outras posições, porque a rotação nos postos de trabalho constitui uma rotina básica. Os trabalhadores são habitualmente divididos em unidades ou grupos de seis ou sete pessoas, em toda a extensão da linha. No caso de ocorrência de um erro, qualquer pessoa pode parar a linha, e o problema é resolvido imediatamente no interior do grupo. Embora em detrimento da especialização, os trabalhadores MEO são capazes de julgar o que acontece e de enfrentar os problemas, à medida que eles ocorrem. Neste contexto, o sistema é flexível, porque os trabalhadores da linha têm poder para pensar e responder a mudanças repentinas.

A essência do MEO reside no fato de que a informação é compartilhada entre os participantes, constituindo um fluxo horizontal. No MO, entretanto, a informação flui verticalmente. $\mathrm{O} M O$ tende a subdividir as pessoas, que são controladas pelo escalão superior ("dividir para poder reinar"). $O$ escalão superior não confia nas pessoas dos níveis inferiores, tratando-as como um recurso substituível.

Os fatores que afetam a produtividade e a competitividade na fábrica, segundo o MEO, incluem os círculos de controle de qualidade, o aperfeiçoamento contínuo ou kaizen, a rotação nos postos de trabalho, a organização do trabalho segundo o conceito de equipe e o sistema just-in-time.

\section{OS CÍRCULOS DE CONTROLE DE QUALIDADE (CCQS)}

Os Círculos de Controle de Qualidade (CCQs) constituem uma forma de autoesclarecimento. Os trabalhadores formam pequenos grupos que abarcam pessoal 
especializado, nāo especializado e engenheiros, nas várias divisôes. Os grupos realizam encontros regulares com periodicidade semanal ou equivalente, durante o período de trabalho ou fora dele, para estudar como elevar a qualidade ou aprender com experiências bem-sucedidas de outras fábricas. Os grupos também discutem o seu próprio processo de produçăo e apresentam idéias para aumentar a produtividade e a qualidade. As recomendações podem referir-se ao layout das máquinas, à ordenação do processamento, às melhorias nas ferramentas e no equipamento, e ao processo de inspeção.

Um aspecto muito importante é como prevenir defeitos causados por operadores distraídos, ou como tornar o processo "à prova de tolos". Algumas vezes, os círculos de controle de qualidade acabam por sugerir que os procedimentos de inspeção sejam internalizados à linha de produção, através do uso de pequenos artifícios para identificar erros. Diferentemente dos métodos de amostragem ao acaso e de inspeção de pontos específi$\cos$, a internalização leva à eliminação total dos defeitos, porque cada parte e cada componente é vistoriado durante o processo de produção. Além disso, o número de inspetores pode ser reduzido.

Os CCQs são habitualmente ligados às associações regionais e nacionais envolvidas com a atividade de controle de qualidade. Casos inovadores e sugestões bemsucedidas são apresentados nos encontros anuais das associações nacionais e prêmios são concedidos para as soluções originais e viáveis. ${ }^{5}$

\section{O APERFEICOAMENTO CONTÍNUO OU KAIZEN}

O aperfeiçoamento contínuo, ou kaizen, é um conceito relativo ao processo manufatureiro, no qual cada membro da unidade de trabalho supervisiona continuamente e cuida de suas condições de trabalho. Normalmente, as fábricas têm objetivos mensais, tais como metas relacionadas com a produção ou com a ausência de defeitos. Aprimoramentos contínuos ajudam a atingir estas metas, encorajando os trabalhadores a descobrir formas mais eficientes e de menor custo de pro- dução. As sugestões apresentadas são examinadas e, dependendo do caso, implantadas imediatamente.

Tanto os círculos de controle de qualidade como as atividades de aperfeiçoamento contínuo derivam de uma abordagem de tipo bottom-up, ou seja, "de baixo para cima". Aqueles que não entendem a fábrica do Leste Asiático acreditam que apenas os trabalhadores especializados podem participar, e que este conceito não

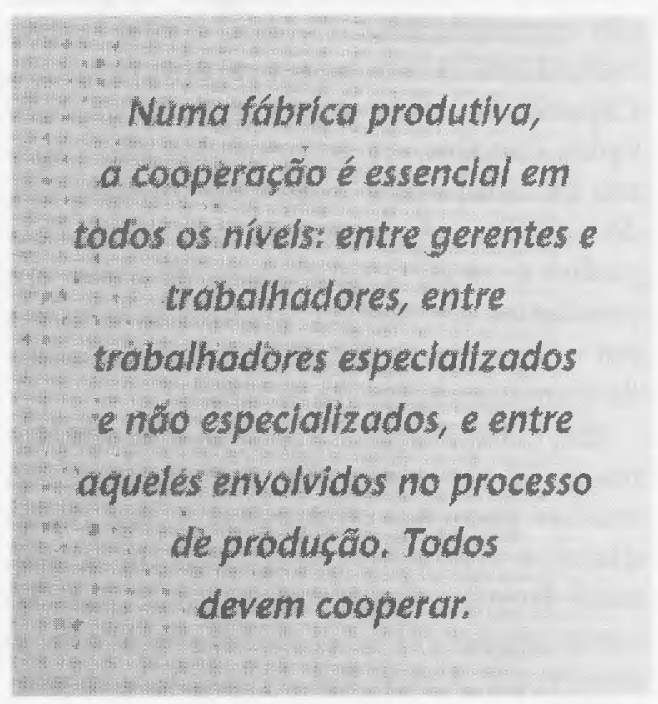

seria aplicável aos trabalhadores não especializados, nas fábricas ocidentais. Trata-se de um equívoco, porque estes esforços não requerem um nível considerável de inteligência ou de conhecimento adquirido. A sabedoria da vida diária é suficiente para produzir idéias úteis e previdentes. Tal como a água, que vagarosamente desgasta a rocha, esforços contínuos podem resultar em maior eficiência e maior produtividade, propiciando, desta forma, maiores lucros e rendimentos. A questão-chave é a percepção dos trabalhadores ao participarem conjuntamente na produção de mercadorias. Esta percepção é formada através da rotação nos postos de trabalho e da formação de equipes.

A idéia subjacente a este esforço de auto-aperfeiçoamento em grupo, normalmente sem qualquer retribuição a curto prazo, é que os trabalhadores têm a garantia de que aumentos na produtividade e qualidade trarão retornos futuros. Neste aspecto, a segurança no trabalho (livre de desemprego ou de demissão) e o
5. No Japão, o prêmio mais prestigiado é o Deming Prize, assim denominado em homenagem ao Dr. W. Edwardas Deming, que foi o primeiro a introduzir os conceitos de controle de qualidade no Japāo, no início dos anos 50. Veja, por exemplo, AGUAYO, R. Dr. Deming: the American who taugh the Japanese about quality. Simon and Shuster Inc., 1990. 
emprego vitalício são condições imprescindíveis para o bom desempenho da fábrica, segundo o MEO.

\section{A ROTAÇÃO NOS POSTOS DE TRABALHO E O TRABALHO DE EQUIPE}

É comum, nas fábricas do Leste Asiático, a prática do rodízio de pessoal nas várias posições de trabalho. Isto permite aos empregados adquirir novas habilidades $e$ entender os diferentes estágios da produção manufatureira. O MEO treina os trabalhadores como atores multifuncionais. Capacitados para o desempenho de múltiplas funções, os empregados são capazes de compensar ausências de trabalho, de orientar o treinamento dos recém-chegados e, mais importante, de estar em condições de exercer diferentes funções em várias linhas de produtos e em casos de transformações de modelos.

Em comparação ao MO, os trabalhadores multi-especializados podem atuar em muitas posições diferentes e, em razão disto, o trabalho é definido de forma mais frouxa. Aoki ${ }^{6}$ coloca essa questão como segue: "A nível de chão de fábrica, a demarcação flexivel das atribuições e responsabilidades e o sistema de rotação nos postos de trabalho podem sacrificar a eficiência estática normalmente obtida através da especialização, num ambiente de mercado estável. Porém, podem contribuir para a eficiência dinâmica da coordenação horizontal, ao encorajar os trabalhadores a aprender, aumentando as capacidades do grupo de trabalho a nivel de fábrica, tanto para promover a sua adaptação às contínuas transformações do mercado e da conjuntura, como para enfrentar as emergências locais de forma autônoma. Tais capacidades podem, também, ajudar a realizar o ajuste da fábrica às novas tecnologias de forma mais suave."

A cooperação constitui um aspecto vi-

6. AOKI, M. Information, incentives and barbaining in the Japanese economy.Cambridge University Press, 1988.

7. Kanban literalmente significa as etiquetas de madeira que exibem o nome de uma tarefa/procedimento.

8. N. R.: em inglês pallet, aportuguesado "palete", é o estrado para empilhamento que depois será transportado. 0 kanban é pendurado num tripé. senvolvido em equipe, sob a orientação de um líder. Este tipo de trabalho em equipe requer um bom sistema de comunicação entre seus membros. Algumas vezes, as equipes desempenham o papel de poderosas unidades de tomada de decisão, arbitrando sobre transferências de trabalho, medidas de controle de qualidade e questões éticas. No que concerne ao processo de produção, a descentralização da tomada de decisões é comum nas fábricas administradas pelo MEO.

Se os administradores, egoistamente, sempre criticarem os trabalhadores pelas perdas ou erros ocorridos, ou se estes últimos pensarem somente em seus próprios interesses (deixando a fábrica após terem sido treinados, por exemplo), esta ficará totalmente dividida, e seus produtos perderão competitividade. Numa fábrica produtiva, a cooperação é essencial em todos os níveis: entre gerentes e trabalhadores, entre trabalhadores especializados e não especializados, e entre aqueles envolvidos no processo de produção. Todos devem cooperar. Uma das desvantagens do sistema de formação de equipes, pelo MEO, pode ser a fragmentação. Em razão disto, os trabalhadores são regularmente intercambiados, de modo a evitar a formação de uma mentalidade paroquial.

\section{O SISTEMA JUST-IN-TIME}

A idéia básica subjacente ao sistema just-in-time é: mercadorias exigidas, nos montantes requeridos, no tempo justo. De forma simplificada, as mercadorias serão fornecidas quando se fizer necessário, na quantidade requerida e no tempo exigido. Esta idéia desenvolveu-se a partir de um método americano de controle de estoques utilizado pelos supermercados. A Toyota tomou conhecimento de sua existência no início dos anos 50 , realizou alguns ajustes e adotou esse seu novo sistema sob a denominação de kan$b a n^{7}$. Kanban é uma tabuleta afixada em um palete ${ }^{8}$, utilizada para carregar partes e componentes. Quando as partes começam a ser utilizadas no fim da linha de montagem, essa tabuleta é deslocada para o posto de trabalho mais próximo. Colocadas ao longo dos postos de trabalho, em toda a extensão da linha de monta- 
gem, essas tabuletas exibem a quantidade de partes e componentes requisitados, - local exato onde são necessitados e o tempo específico de entrega. As divisões e as oficinas upstream, situadas mais ao início da cadeia produtiva, recolhem essas tabuletas regularmente, $e$, de acordo com as suas observaçōes, iniciam a produção de suas partes e componentes, solicitando os produtos que lhes são necessários e despachando os seus próprios kanban para outros locais de trabalho ainda mais ao início dessa cadeia. As solicitações continuam a tramitar para trás, até o próprio início da cadeia de produção, e, em contrapartida, os volumes requisitados são despachados para frente, no tempo demandado, um por um. $\mathrm{O}$ sistema kanban é diretamente conectado com o do mercado. Quando a demanda muda, os ajustes podem ser implantados imediatamente, retrocedendo das divisões downstream, situadas mais ao final da cadeia produtiva, até as oficinas upstream, localizadas mais ao início desta.

A idéia subjacente a este sistema é que as partes utilizadas numa linha de montagem deverão ser fornecidas imediatamente à medida que são utilizadas, exatamente como ocorre com as mercadorias expostas nas prateleiras dos supermercados, que são repostas quase que simultaneamente ao ato da compra. As tabuletas (kanbans) fornecem instruçōes ou encomendas para o estágio prévio de produção, que são interpretadas como sinais para o início da fabricaçāo das partes e dos componentes requisitados. $\mathrm{O}$ sistema kanban é, portanto, um sistema de informações que liga o estabelecimento de venda final do produto aos primeiros fornecedores de partes, situados no próprio início da cadeia produtiva, garantindo que somente a quantidade necessária seja fabricada em cada estágio de produção. O sistema minimiza as quantidades armazenadas e reduz os custos de estocagem, rebaixando, em consequiência, os custos de produção.

O sistema kanban possui três características fundamentais. A primeira baseiase na utilização do conceito de "defeito zero" para as partes e os componentes. A linha de montagem final deverá parar se alguma parte apresentar baixa qualidade, de modo que se pode prescindir de ins- peção no local de entrega. Isto leva à sua segunda característica: as divisões ou as oficinas ou os subcontratados (upstream), situados mais ao início da cadeia produtiva, responsáveis pelo fornecimento de partes e de componentes, devem possuir o mesmo nível e os mesmos padrões mantidos pela montadora final, em termos de produtividade, qualidade, preço, tecnologia e tempo de entrega. Em outras palavras, o grau de padronização e de

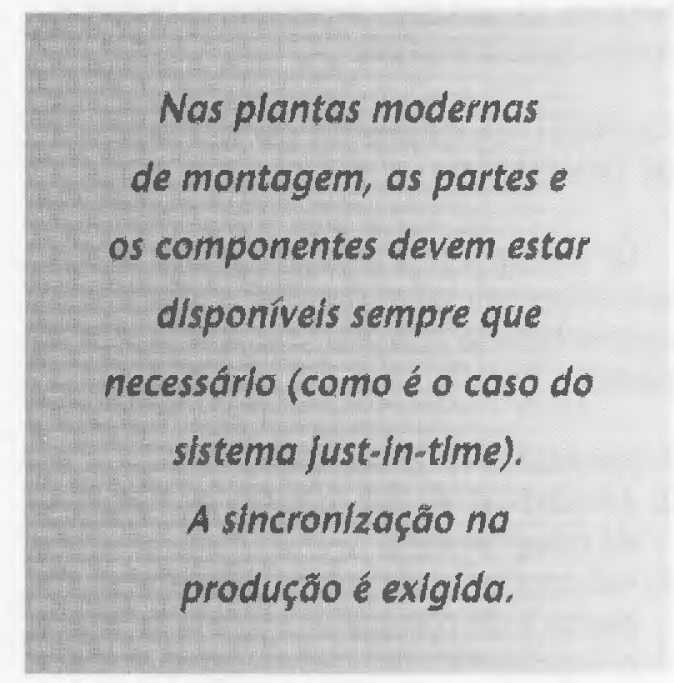

uniformidade dos produtos é fundamental, assim como a sincronização da produção. Considerando que os ajustes empreendidos se refletem na demanda final, os trabalhadores são requisitados para desempenhar papéis multifuncionais. Aqueles considerados inúteis ou ociosos são transferidos para outras funções. Esta constitui a terceira característica. $\mathrm{O}$ sistema não é fácil de ser adotado. A Toyota levou quase vinte anos para alcançar o estado da arte em que se encontra o seu atual sistema.

\section{OS RELACIONAMENTOS INTERFIRMAS}

Nos países em desenvolvimento, é freqüentemente difícil encontrar fabricantes confiáveis de partes e de componentes, em termos de tecnologia, qualidade e tempo de entrega. Desta forma, as montadoras tendem a produzir internamente as partes e componentes de que necessitam (verticalização interna). Por que, então, os países do Leste Asiático - particularmente o Japão, Taiwan e Coréia - utili- 
zam empresas autônomas de partes e de componentes, integrando-as no processo de montagem através de subcontratações (verticalização externa)? Qual é o raciocínio econômico que orienta estes relacionamentos interempresas, envolvendo montadoras (empresas principais) e subcontratadas? Podem ocorrer casos em que as empresas principais não disponham de tecnologia para desenvolver uma parte específica. Mais provavelmente, entretanto, a razão econômica que determina as relações montadoras/subcontradas envolve custo.

\section{AS QUESTÕES INERENTES AO CUSTO DE TRANSAÇÃO}

Se a empresa principal pretende desenvolver um novo produto, existem três opções básicas relacionadas com as novas partes:

1. produzi-las internamente;

2. adquiri-las de fabricantes de partes e de componentes;

3. subcontratar empresas produtoras de partes e de componentes para fornecer o suprimento necessário (grupos seletos de fornecedores).

Na primeira opção, há que se considerar os custos de implantação, operacionais e de produção. A segunda opção requer um exame dos custos de aquisição e transporte, enquanto que a terceira envolve custos de aquisição, transação e transporte. No curto prazo, o segundo caso parece menos oneroso, se comparado com as demais alternativas, contanto que as partes adquiridas sejam de boa qualidade e que sua entrega se faça de forma conveniente, nas quantidades solicitadas e sem qualquer atraso. Entretanto, se forem levados em consideração os custos ex-post e as questões de longo prazo, esta pode não ser a melhor opção.

A segunda opção pode envolver a substituição de fornecedores de partes e componentes em função dos altos preços, da baixa qualidade, de erros nas especificações, da instabilidade no suprimento, em termos de volume ou da incerteza na entrega. Como resultado, a empresa principal deve estar voltada para a procura permanente de novos forne- cedores. Porém, a obtenção de um suprimento estável de partes e componentes não é um fato garantido. No longo prazo, estes custos inerentes à escolha de fornecedores são muito elevados para serem ignorados.

Se a empresa principal puder estabelecer relacionamentos sólidos com as subcontratadas fornecedoras de partes, através de assistência técnica, gerencial ou financeira, em certos casos a terceira opção pode ser menos onerosa no longo prazo. Por essa razão, a principal consideração da empresa montadora, ao decidir sobre a implantação ou não de um sistema de subcontratações, deve referirse à comparação entre os custos de verticalização interna e de subcontratação. Em outras palavras, se os custos de verticalização interna são mais elevados, presumivelmente:

\section{Custos de implantação, Custos de transação, custos operacionais aquisição, transporte e de produção na verticalização interna e assistência na subcontratação}

Os custos de transação são definidos como os gastos relacionados com o "funcionamento do sistema econômico", ou como os custos dos "atritos" sociais e econômicos ${ }^{9}$. Coase ${ }^{10}$ apresenta os seguintes exemplos de custos de transação: custos relativos à descoberta de preços relevantes; custos decorrentes da negociação e conclusão de contratos separados para cada transação de troca; custos referentes à procura de contrapartes para contratos de longo prazo, com a finalidade de evitar riscos e, finalmente, custos referentes a impostos sobre transações comerciais.

Os custos associados com contratos ou subcontratos incluem preparação, negociação, e garantia do acordo. Se a sociedade é fundamentada na confiança mútua, os custos de transação são pequenos; entretanto, se for baseada na desconfiança, eles serão muito elevados. Como exemplo extremo, pode-se mencionar o fato de que os comerciantes chineses raramente utilizam contratos escritos na sua atividade diária porque possuem fortes ligações de natureza associativa (denominadas bang). Se alguém viola um acordo verbal, esta pessoa será excluída 
da sociedade. Desta forma, os custos de transação são negligenciáveis nas tradições chinesas de negócios, devido aos severos custos das sançōes.

Outro exemplo é observado nos grupos industriais coreanos, baseados nos relacionamentos comerciais familiares ou consangüíneos. No interior do grupo, as empresas compartilham as informaçōes, o que facilita a formação de relacionamentos com subcontratadas, sem elevados custos de transação.

Os custos de assistência da empresa principal para as subcontratadas incluem a transferência de know-how técnico e gerencial, o fornecimento de projetos, matérias-primas, matrizes, ferramentas e instrumentos básicos $\mathrm{e}$, em alguns casos, $\mathrm{o}$ suporte financeiro.

Nas plantas modernas de montagem, as partes e os componentes devem estar disponíveis sempre que necessário (como é o caso do sistema just-in-time). A sincronização na produção é exigida. Esta é a razão da importância vital de um nível padronizado de fornecedores de partes e de componentes, em termos de qualidade, quantidade e entrega, conforme explicado anteriormente. Quanto maior o grau de sincronização, mais barato será o custo de assistência e menor o tempo de produção.

A decisão de fazer partes e componentes, adquiri-los diretamente ou comprálos através de cadeias de fornecedores seletos depende de uma série de fatores complexos. Entretanto, do ponto de vista de redução de custos, o sistema de subcontratação do MEO tem funcionado bem nas plantas modernas de montagem, apresentando maior eficiência e menor custo a longo prazo. Womack, Jones e Roos ${ }^{11}$ escreveram: "Em 1990, a Toyota oferecia aos consumidores de todo o mundo tantos produtos quanto a General Motors, ainda que tenha metade do tamanho desta. A mudança na produção e na especificação dos modelos em linhas de produção em massa têm levado muito tempo e custado uma fortuna para as empresas. Em contraposição, um produtor proeminente e enxuto como a Toyota, necessita da metade do tempo e do esforço de um produtor em massa como a GM para projetar um novo modelo. Assim sendo, a Toyota pode oferecer duas vezes mais veiculos com o mesmo orçamento para desenvolvê-los"

\section{PRINCÍPIOS E CARACTERISTICAS DO SISTEMA DE SUBCONTRATACÕ̃ES UTILIZADO PELO MÉTODO DO EXTREMO ORIENTE (MEO)}

Os aspectos organizacionais do relacionamento montadora-fornecedor possuem vários princípios e características. Primeiro, o sistema funciona bem para produtos finais como automóveis e eletrônicos, que requerem milhares de partes e compo-

Se a informação flui suavemente
neste sistema - a tecnologia
partindo da empresa principal
para as subcontratados e as
intormaçôes sobre o custo de
produção refluindo das
subcontratados para a empresa
principal - todas as empresas
partilham não somente o risco,
mas também um relational
quasi-rent, isto é, um beneficio
relacional comparável à renda.

nentes, ou para artigos de vestuário, que exigem muitos processos segmentados. Se os processos de produção não puderem ser divididos, ou se os bens finais demandarem poucas partes, as fontes externas de suprimento não serão necessárias.

Segundo, as empresas de partes e componentes normalmente formam uma estrutura em múltiplas camadas, com uma empresa principal suprindo a planta de montagem final. Este tipo de estrutura piramidal reflete o primeiro aspecto, ou seja, uma divisão de trabalho dentro dos processos de produção. Por exemplo, ao final dos anos 70 , verificou-se que a Toyota tinha 122 subcontratadas de primeira linha (ou camada), 5.436 subcontratadas de segunda linha e 41.703 subcontratadas de terceira linha. Através da construção desta rede de relações, a Toyota assumiu o topo de uma pirâmide de 35.768 empresas. Um carro é composto por mais de 20 mil partes, e, mesmo agora, é ainda surpreendente constatar que tantas firmas estejam envolvidas no seu processo manufatureiro.
11. WOMACK, J.P.; JONES, D.T.; ROSS, D. The machine that changed the world. Rawson Associates, 1990 


\section{II}

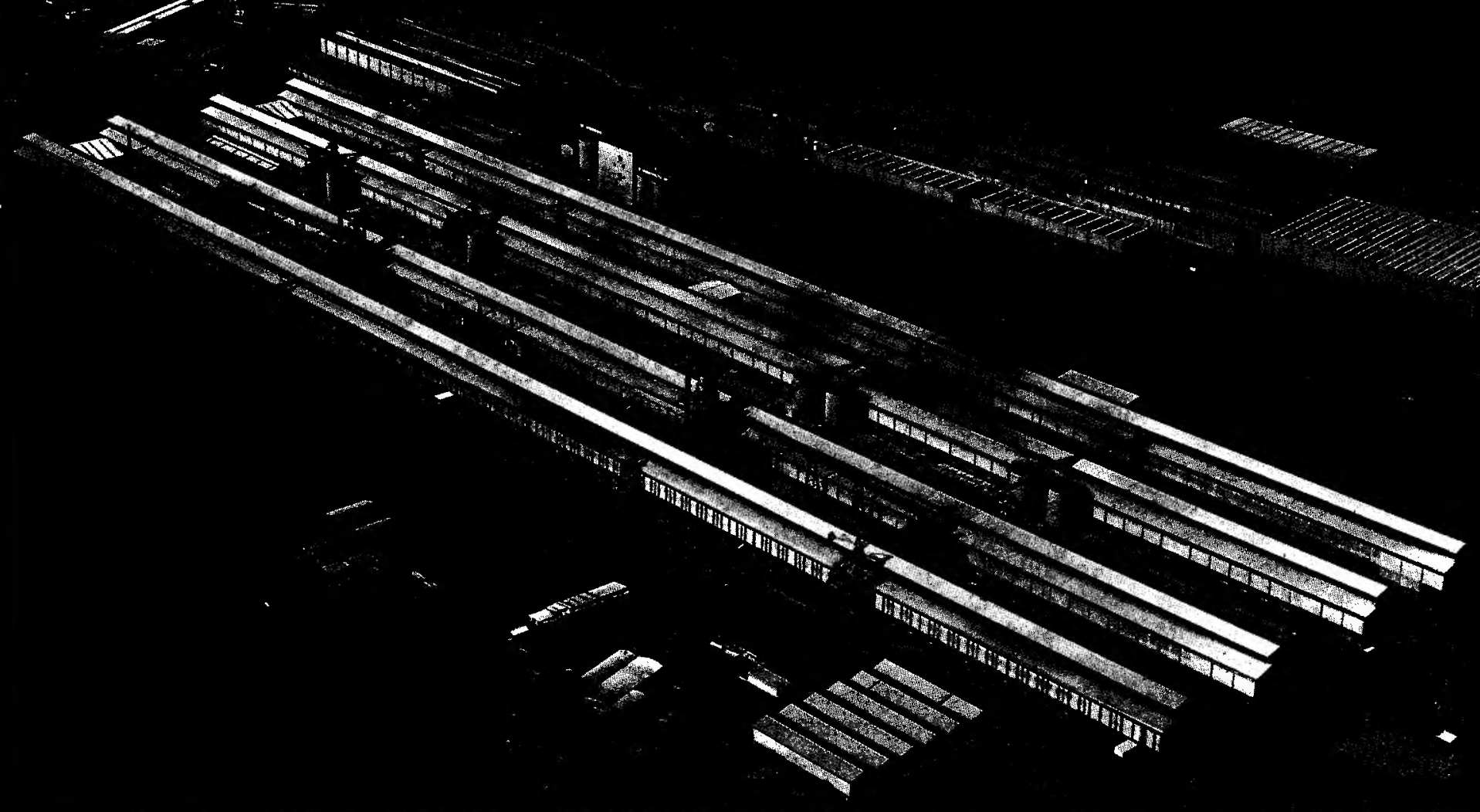

\section{A Companhia Brasileira de Alumínio confila no futuro.}

Como conseqüência, investe no aumento de produção, através da informatização. Dedica atenção especial ao Meio Ambiente.

Reduz custos e garante milhares de empregos.

É esta a fórmula de trabalho que a Companhia Brasileira de Alumínio desenvolve confiando no futuro.
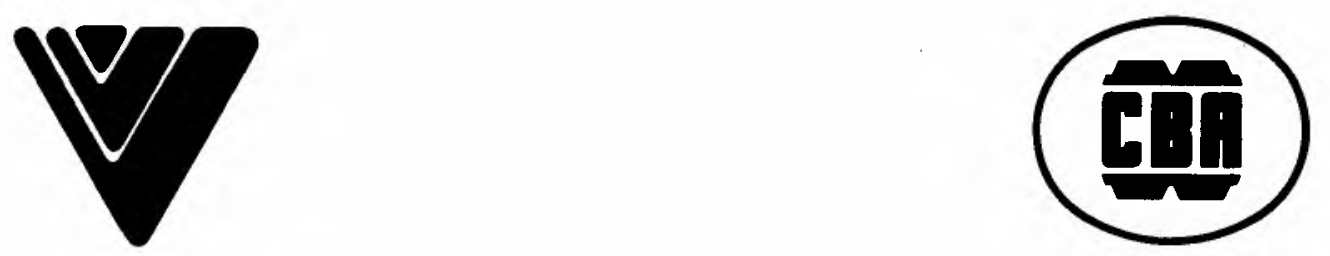

COMPANHIA

BRASILEIRA DE

ALUMÍNIO 


\section{BEM-VINDO AO FUTURO.}

A Scania respeita muito a evolução tecnológica de seus caminhões.

Porque respeita ainda mais o usuário. Por isso, não se limita a

\section{Diversos caminhões fabricados no}

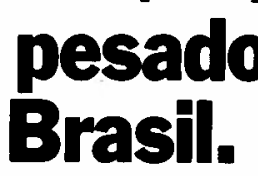
acompanhar a evolução presumível das coisas. No desenvolvimento dos

faz revolução. Está sempre à frente.

Como agora, por exemplo, ao lançar em sua linha 94, a nova cabine Topline - a mais revolucionária cabine de caminhão.

\section{Mas, quantos the oferecem uma cabine como esta, de alta produtividade? \\ Projeto profundamente ergonômico, dirigido para o esforço do motorista em seu. \\ difícil trabalho de cada dia. Uma cabine que no futuro será, sem dúvida, seguida pelos outros caminhões. (Mas, aí, a Scania já estará a quilômetros de distância...).}

Vá ao Concessionário Scania conhecer o novo caminhão 94. Você vai ficar fascinado ao conhecer, detalhe por detalhe, a cabine Topline: mais alta internamente; suspensão a ar também nos modelos $T$, entre outras inovações.

E, mais uma vez, você comprovará porque os caminhões.Seania estão

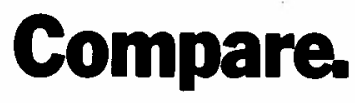
anos e anos na dianteira. Na qualidade. No des $\mathrm{Na}$ interação motorista/caminhão.

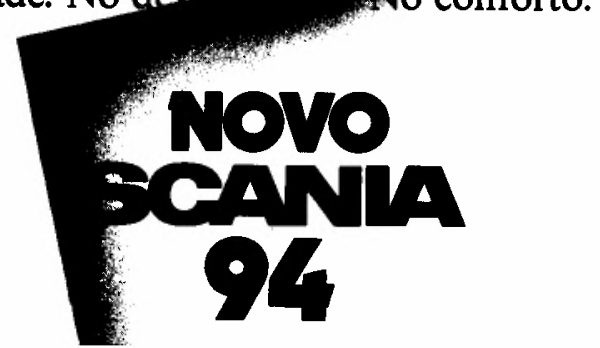


12. Arrow (ARROW, K. The Iimits of organization. W.W. Norton and Co., 1974. p. 23) argumenta que "A confiança é um importante lubrificante do sistema social. Ela é extremamente eficiente; ter um grau justo de confianca nas palavras dos outros elimina um grande número de problemas... Esses valores (confiança e outros similares, tais como lealdade ou verdade) aumentam a eficiência do sistema, capacitando-o a produzir mais bens ou mais de qualquer valor tido em alta conta".

13. Recentemente, este sólido acordo de cavalheiros tem se quebrado e os fabricantes de partes atualmente vendem seus produtos por toda parte, sem considerar os seus vínculos com os grupos, devido à recessão e ao rápido avanco tecnológico. Como resultado, as montadoras mais fracas necessitam de partes high-tech de outras famílias keiretsu.

\section{AOKI, M. Op. cit.}

15. Joka-machi, significa, literalmente, "cidade do castelo", onde um lorde construiu um castelo e pessoas reuniram-se em torno para servi-lo, na época feudal. Exemplos de jokamachi modernos são a Toyota, perto de Nagoya, Matsuhita, perto de Osaka, Mazda, perto de Hiroshima e agrupamentos de alta tecnologia a recém-criados.
Terceiro, as subcontratadas possuem vínculos estreitos com as empresas de escalão superior e seus relacionamentos são quase semipermanentes. Os contratos têm normalmente a duração de cinco ou seis anos, dependendo do tempo de desenvolvimento de um novo modelo, sendo prorrogados repetidamente. Os ajustes de preços são realizados duas vezes por ano. A empresa principal geralmente calcula uma determinada margem de lucro para as subcontratadas, tendo em conta os custos de produção das partes e dos componentes. Além disto, a empresa principal fornece o projeto, a tecnologia, as ferramentas para o processamento e, algumas vezes, assistência financeira, na forma de capital e/ou empréstimos. Em contrapartida, um suprimento estável de partes e componentes é garantido pelas subcontratadas, com uma qualidade muito próxima à de "defeito zero" nas mercadorias.

Quarto, cooperação e confiança são ${ }^{12}$ aspectos críticos para manter a cadeia hierárquica de suprimento em movimento. A informação entre os membros do grupo deve fluir sem qualquer empecilho, tanto vertical quanto horizontalmente. Este é o motivo pelo qual algumas montadoras de automóveis, no Japão, organizam associações com características de clubes, entre os membros dos sistemas kyoryoku-kai ou do vertical keiretsu. Por exemplo, a Toyota possui um grupo Kyoho-kai, a Nissan um Takara-kai e a Mitsubishi um Kashiwa-kai. O grupo Takara-kai é composto de, aproximadamente, 104 companhias de autopeças e componentes, que são afiliadas ou subsidiárias da Nissan. Além disso, mais de 60 fornecedores independentes de peças e acessórios formam um outro grupo de suporte da Nissan, denominado grupo Shoho-kai. O grupo de primeira linha inclui, aproximadamente, 120 membros associados، o de segunda linha, mais de 950 empresas. Geralmente, essas associações são mutuamente excludentes - cada membro do grupo não vende seus produtos a outras associações. Esta lealdade ou "boa conduta" é recompensada por pedidos de longo prazo, estáveis, do escalão superior ${ }^{13}$, conforme mencionado anteriormente (ver figura 1).

Finalmente, se a informação flui suavemente neste sistema - a tecnologia par- tindo da empresa principal para as subcontratadas e as informações sobre o custo de produção refluindo das subcontratadas para a empresa principal - todas as empresas partilham não somente o risco, mas também um relational quasi-rent, isto é, um benefício relacional comparável à renda. ${ }^{14} \mathrm{~A}$ partir do momento em que os relacionamentos são estabelecidos, o poder de barganha entre a empresa principal e as subcontratadas passa a depender do grau de especialização técnica, dos custos envolvidos com possíveis ameaças de quebra da relação, e do nível do seguro - as subcontratadas pagam um prêmio por aceitar preços ligeiramente mais baixos, durante o período em que recebem solicitações de longo prazo.

\section{A PROMOÇ̃̃O DAS PEQUENAS E MÉDIAS EMPRESAS (PMES): A EXPERIÊNCIA JAPONESA}

Basicamente, existem dois tipos de pequenas e médias empresas (PMEs). Um é estreitamente relacionado com a localidade, fabricando produtos inerentes ao ambiente local, tais como têxteis e porcelanas tradicionais. $O$ outro refere-se a grandes instalações industriais de montagem, que integram redes de suprimentos numa área específica. No Japão, esta integração é conhecida como joka-machi ${ }^{15}$, ou, simplesmente, a cidade do complexo industrial.

As PMEs desempenham, também, um importante papel no setor de serviços. Varejistas e atacadistas, na sua maior parte constituídos por PMEs, são quase sempre encontrados próximos ao consumidor, reunindo-se e fixando-se nesses locais. As PMEs têm sido e continuam a ser um fator-chave na estrutura empresarial japonesa e, por esta razão, é importante considerar sua evolução e desenvolvimento. Esta parte do texto examina esta evolução, especialmente as experiências do período pós Segunda Guerra Mundial. O sistema de subcontratações japonês é, desta forma, introduzido e discutido.

No Japão, a subcontratação é comum não apenas nas indústrias pesadas, tais como as de automóveis e de produtos metálicos, mas também nas indústrias leves, como têxteis e vestuário. A partilha das informações e a cooperação entre as 


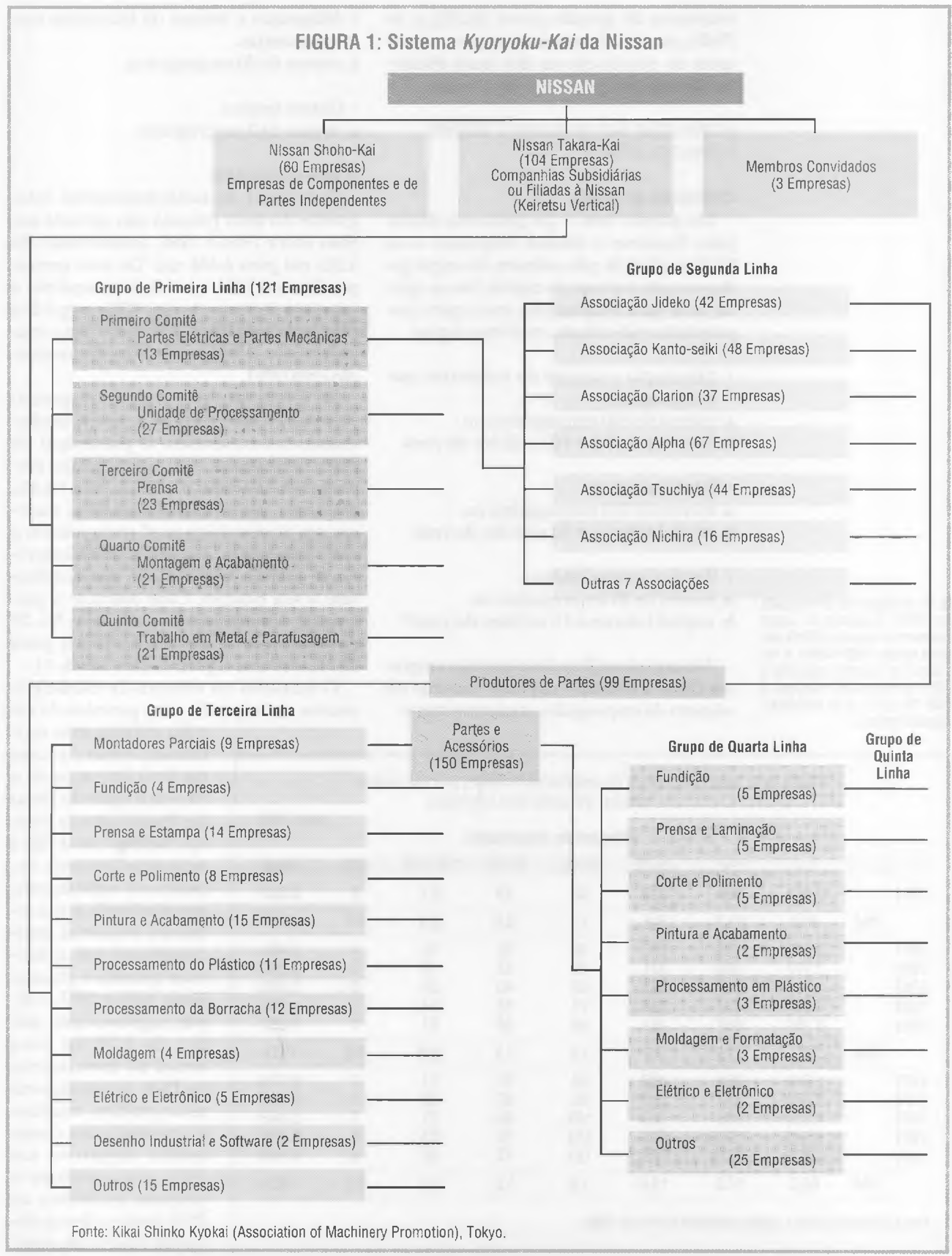


16. A Lei Básica fol promulgada em 1963. Tomando-se como parâmetro a taxa de câmbio daquela época, US $\$ 1=\$ 360,0$ tamanho do capital equivale a US\$ $278 \mathrm{mil}$ ( $=\Varangle 30$ milhões): $\mathrm{e}$ US\$ $28 \mathrm{mIl}$ ( $=\$ 10$ milhoes $)$, respectivamente. empresas de grande porte (EGPs) e as PMEs, através de subcontratações, constituem os pontos-chaves dos mais eficientes sistemas de produção do mundo.

\section{A EVOLUÇ̃̃O DAS PEQUENAS E MÉDIAS EMPRESAS (PMES)}

\section{Definição de PMEs}

De acordo com a Lei Japonesa Básica para Pequenas e Médias Empresas, uma PME é definida pelo número de empregados ou pelo volume de capital. Isto se aplica tanto para corporações como para propriedades individuais, conforme segue:

- Mineração e setores de indústrias manufatureiras:

a. menos de 300 empregados, ou

b. capital inferior a $\mathbf{1 0 0}$ milhões de yens.

- Setor atacadista:

a. menos de 100 empregados, ou

b. capital inferior a 30 milhões de yens.

- Varejo e outros setores:

a. menos de 50 empregados, ou

b. capital inferior a 10 milhões de yens ${ }^{16}$

No caso específico das pequenas empresas (PEs), a definição depende somente do número de empregados, conforme segue:
- Mineração e setores de indústrias manufatureiras.

a. menos de 20 empregados.

- Outros setores:

a. menos de 5 empregados.

\section{Estabelecimentos}

O número de estabelecimentos integrantes do setor privado não agrícola dobrou entre 1954 e 1986, aumentando de 3.285 mil para 6.494 mil. Do total correspondente a 1986, os setores atacadista e varejista representaram $47 \%$, seguidos pelo setor serviços $(23 \%)$, pelo setor manufatureiro (13\%) e pelo setor de construção civil ( $9 \%$ ).

As PMEs têm sido sempre responsáveis por mais de $99 \%$ de todos os estabelecimentos comerciais. $O$ percentual de estabelecimentos com um a quatro empregados diminuiu de $80,2 \%$ para $68,2 \%$, enquanto que os estabelecimentos maiores, em termos de pessoal, aumentaram a sua participação, exceção feita às empresas de grande porte (EGPs), que mantiveram a sua posição. Cabe destacar o percentual dos estabelecimentos com 5 a 29 pessoas, que se elevou de $17,8 \%$ para $28,1 \%$, durante o período (ver tabela 1 ).

$\mathrm{O}$ aumento no número de estabelecimentos correspondeu aos períodos de rápido crescimento econômico, como é o caso do final dos anos $60 \mathrm{e}$ 70 . Sob a égide do Plano de Duplicação da Renda Nacional (1961-70), a economia japonesa expandiu-se rapidamente, aprofundando a sua estrutura industrial, principalmente nas indústrias química e pesada. Entre 1961 e 1973, o Japão registrou uma média de $9,2 \%$ na taxa anual de crescimento do PNB. A primeira crise do petroleo, entretanto, produziu um crescimento negativo em 1974, que constituiu o primeiro decréscimo do PNB desde o fim da Segunda Guerra Mundial. 
Desde então, a taxa de crescimento nunca mais excedeu o patamar de $6 \%$ ao ano, mantendo uma média de $4,4 \%$, entre 1975 e 1990. Ao mesmo tempo, a economia japonesa foi se modificando gradualmente, passando de uma estrutura econômica baseada na indústria para uma orientada para o setor de serviços. A participação do setor terciário no PIB evoluiu de $46 \%$, em 1965, para $56 \%$, em 1989, enquanto a do setor manufatureiro declinou de $34 \%$ para $30 \%$, durante o mesmo período.

Estes fatos detonaram uma verdadeira explosão das pequenas empresas, abrangendo negócios com capital de risco no comércio e nos setores de serviços.

\section{Pessoas empregadas}

O emprego no setor privado não-agrícola também refletiu as flutuações econômicas. O número de pessoas empregadas, nesse setor, aumentou de 17,6 milhões, em 1954, para 49,0 milhões, em 1986. Entre 1960 e 1972, registrou-se um crescimento anual de $4,4 \%$, diminuindo para $1,9 \%$, entre 1975 e 1986 . Do total registrado em 1986 (49 milhões), os setores atacadistas e varejistas representaram $32 \%$, seguidos pelo setor manufatureiro $(27 \%)$, pelo setor de serviços $(20 \%)$ e pelo setor de construção civil (10\%).

A percentagem de pessoas empregadas pelas empresas de grande porte (EGPs) foi ainda maior durante os anos $60(16-17 \%)$, mas declinou para $11,6 \%$, em 1986. As EGPs começaram a tomar medidas drásticas para enfrentar os altos custos de mão-de-obra e energia, especialmente após a segunda crise do petróleo, em 1979. A mão-de-obra foi substituída pela maquinaria, principalmente por robôs, durante os anos 80 . Por outro lado, a percentagem de pessoas empregadas em estabelecimentos com 10 a 49 pessoas aumentou de $26,7 \%$, em 1954 , para
TABELA 2: Japão: número de empregados por tamanho (setor privado nẫo agrícola)

(em 1.000)

Número de empregados

\begin{tabular}{ccccccc}
$5-9$ & $10-29$ & $30-49$ & $50-99$ & $\mathbf{1 0 0 - 2 9 9}$ & 300 & Total \\
2.369 & 3.385 & 1.320 & 1.263 & 1.407 & 2.841 & 17.618 \\
\hline 13,4 & 19,2 & 7,5 & 7,2 & 8,0 & 16,1 & 100,0 \\
\hline .763 & 3.707 & 1.423 & 1.514 & 1.852 & 2.935 & 19.582 \\
2.956 & 4.277 & 1.835 & 2.068 & 2.554 & 4.021 & 23.158 \\
3.286 & 5.157 & 2.350 & 2.698 & 3.239 & 4.634 & 27.241 \\
3.902 & 6.194 & 2.786 & 3.243 & 3.812 & 4.871 & 31.076 \\
4.413 & 6.856 & 3.141 & 3.629 & 4.342 & 5.745 & 35.029 \\
\hline 12,6 & 19,6 & 9,0 & 10,4 & 12,4 & 16,4 & 100,0 \\
4.893 & 7.664 & 3.497 & 4.111 & 4.932 & 6.120 & 38.794 \\
5.355 & 8.275 & 3.588 & 4.070 & 4.661 & 5.707 & 39.641 \\
6.135 & 9.210 & 3.854 & 4.342 & 4.809 & 5.290 & 42.295 \\
6.770 & 10.120 & 4.246 & 4.731 & 5.137 & 5.326 & 45.720 \\
7.214 & 11.134 & 4.648 & 5.103 & 5.734 & 5.676 & 48.995 \\
\hline 14,7 & 22,7 & 9,5 & 10,4 & 11,7 & 11,6 & 100,0 \\
\hline
\end{tabular}
.

Fonte: Idem Tabela 1.

$32,2 \%$, em 1986. Estabelecimentos de outras dimensões também expandiram sua participação relativa durante o período, exceto aqueles com um a quatro empregados (ver tabela 2).

Durante os anos 80 , ocorreu uma transformação fundamental no sistema de distribuição. Este sistema, no Japão, era considerado muito complexo devido à sua estrutura em múltiplas camadas de atacadistas e da existência de muitos varejistas autônomos de pequeno porte. A emergência dos supermercados e dos grandes estabelecimentos comerciais ao largo das estradas, assim como a não utilização dos intermediários, alteraram o estilo de vida dos consumidores e diversificaram suas preferências. Outro fator foi a valorização gradual do yen em relação ao dólar após o choque promovido por Nixon, em 1971 (abandono das taxas de câmbio fixas). Aproveitando a vantagem propiciada pela existência de um yen mais forte, as pequenas empresas (PEs) expandiram a sua importação de bens manufaturados. Além disso, algumas PEs também investiram diretamente no exterior, especialmente ao final dos anos 80, após o Acordo Plaza, de 1985. Essas tendências de crescimento podem ser examinadas nas tabelas 1 e 2 , nas quais se pode verificar um decréscimo no percentual de estabelecimentos com 
um a quatro empregados, bem como um aumento na percentagem de estabelecimentos médios.

Em suma, as PMES contribuíram, no Japão, com mais de $80 \%$ do número total de empregados do setor privado não-agrícola, e mais de $99 \%$ dos estabelecimentos do setor.

\section{A CLASSIFICAÇÃO DO SETOR MANUFATUREIRO POR TAMANHO}

No setor manufatureiro, 436.009 estabelecimentos empregaram 10.893 pessoas, produzindo um total de US\$ 529,3 bilhões (valor adicionado), em 1986 (ver tabela 3). As pequenas empresas, com 4 a 19 empregados, representaram $76,7 \%$ do total dos estabelecimentos, e 24,7\% do número de pessoas envolvidas, enquanto as consideradas de médio porte, com 20 a 299 pessoas, responderam por $22,6 \%$ e $47,6 \%$, respectivamente. As EGPs, com mais de 300 pessoas, representaram apenas $0,9 \%$ dos estabelecimentos, mas empregaram $27,8 \%$ do total da força de trabalho.

Os maiores produtores de valor adicionado foram os estabelecimentos com mais de 1.000 pessoas, responsáveis por $23,4 \%$ do total do valor criado no setor, em 1986. Estabelecimentos com 500 a 999 pessoas produziram $11,3 \%$, seguidos pelos estabelecimentos de 100 a 199 pessoas
$(11,1 \%)$, e pelos de 50 a 99 pessoas $(10,7 \%)$. As PEs, com 4 a 19 pessoas, contribuíram com $14,8 \%$ do valor adicionado. É notável que os estabelecimentos com 50 a 199 pessoas tenham produzido mais valor adicionado do que aqueles com 200 a 499 pessoas. Geralmente, em termos de valor adicionado por empregado, quanto maior o tamanho, maior o valor. Na média, o valor adicionado por empregado na produção do setor manufatureiro foi de US\$48,6 mil.

Em síntese, as PMEs foram responsáveis por $99 \%$ dos estabelecimentos, $72 \%$ do emprego e $57 \%$ do valor adicionado no setor manufatureiro, em 1986.

\section{AS POLÍTICAS GOVERNAMENTAIS PARA AS PMES}

Historicamente, o suporte governamental para as PMEs originou-se da compreensão do fato de que estas estavam sendo injustamente tratadas, em razão de sua posição desvantajosa nas negociações com as EGPs, de seu acesso limitado às instituições financeiras convencionais, assim como do desenvolvimento tecnológico e de seus grandes desníveis, em termos de renda e produtividade. Além disto, até os anos 70 , no Japão, os círculos políticos e acadêmicos foram marcados por uma forte influência marxista, que defendia a tese de que as EGPs exploravam as PMEs. Este argumento, relativo à "estrutura dual", induziu o governo a adotar políticas de proteção às PMEs, conforme será explicado posteriormente.

As políticas governamentais para as PMEs podem ser divididas, principalmente, em três categorias: as de eliminação das restrições às transações, com o objetivo de aumentar a produtividade; as de criação de facilidades para a obtenção de recursos financeiros, através do esta- 
belecimento de taxas de juros preferenciais e de incentivos fiscais; e as de desenvolvimento tecnológico.

\section{POLÍTICAS DE ELIMINAÇÃO DE RESTRIÇÕES}

Em 1949, o governo instituiu uma Lei que autorizava as PMEs a formar cooperativas e a fortalecer a sua atividade econômica através da constituição de grupos dinâmicos. Recomendou, ainda, que as PMEs realizassem as suas compras de materiais, bem como as suas negociações e vendas de produtos, de forma conjunta, e que estabelecessem empréstimos entre os seus membros. Com a finalidade de inibir pressões indevidas nas subcontratações, por parte das EGPs, o governo introduziu uma lei, em 1956, que protegia as PMEs dos atrasos nos pagamentos realizados pelas empresas de grande porte (ver tabela 4).

Esta Lei definiu, formalmente, os relacionamentos afetos às subcontratações, entre a empresa principal e as subcontratadas, assim como regulamentou os procedimentos operacionais para a celebração de contratos, tais como documentação e solicitações escritas. Nos casos de atrasos nos pagamentos, a lei estabeleceu que a empresa principal deveria pagar juros incorridos.

A proteção governamental em relação às PMEs foi intensificada em 1963, com a introdução de três novas leis. A mais importante foì a Lei Básica para as Pequenas e Médias Empresas, que visou a elevar o seu status econômico e social, através do aumento da produtividade e da correção das desvantagens. A lei recomendou a adoção, pelo governo, de medidas integradas para as PMEs, nas seguintes áreas:

a. modernização das instalações;

b. aperfeiçoamento da tecnologia;

c. racionalização da gestão;

d. aperfeiçoamento da estrutura das PMEs;

e. eqüidade nas transações;

f. aumentos na demanda;

g. inibição do excesso de competição ou reserva de mercado;

h. estabelecimento de boas relações de trabalho.
Além disso, a lei exigia que o Departamento das Pequenas e Médias Empresas, vinculado ao MTTI (Ministry of International Trade and Industry), elaborasse um relatório anual, "O Livro Branco sobre as Pequenas e Médias Empresas", para fins de apresentação ao Congresso.

$O$ rápido crescimento da economia japonesa, durante os anos 60, aperfeiçoou a sua estrutura industrial; complexas cadeias de suprimento foram formadas, particularmente nas indústrias eletrônica e au-

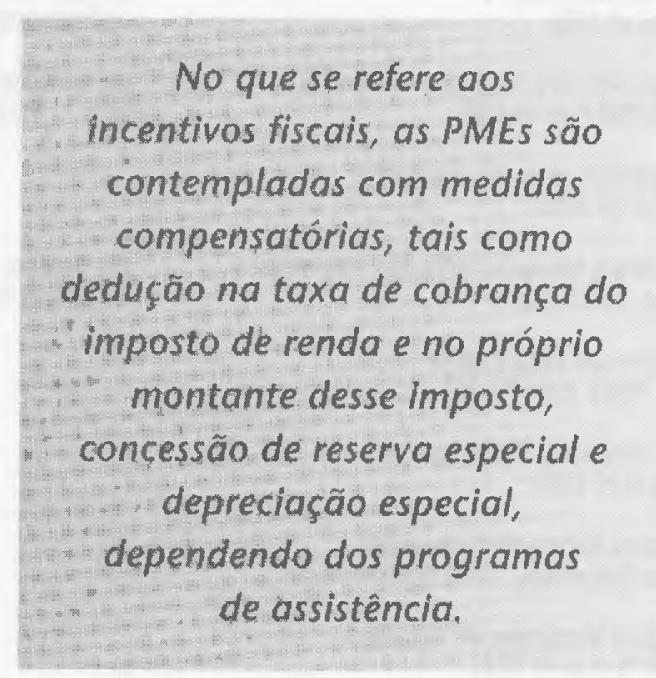

tomobilística. Refletindo esta tendência econômica, em 1970 fui introduzida a Lei de Promoção para a Subcontratação de Pequenas e Médias Empresas, com o objetivo de modernizar e garantir maior eqüidade nas transações entre as empresas principais e as subcontratadas. Esta Lei fortaleceu uma organização denominada Associação de Promoção das Subcontratadas, atribuindo-lhe o papel de intermediação empresarial. A Associação elaborou listas de empresas que queriam estabelecer relações de subcontratações. Além disso, reforçou a autoridade desta Associação para arbitrar sobre disputas entre empresas.

A Lei para Acordos na Atividade Varejista em Relação às Empresas de Grande Porte, promulgada em 1973, estipulou que os estabelecimentos de ampla abrangência territorial não poderiam monopolizar os mercados. A idéia básica foi proteger os pequenos varejistas autônomos daqueles de grande porte, ou, simplesmente, de estabelecer reserva de mercado para os pequenos, em áreas de comunidades ocupadas por locais (como a Europa). ${ }^{17}$
17. Esta Lei foi severamente criticada pelo Estados Unidos no Structural Impediment Initiative (SII), durante a administração Bush. A TOYSO'US abriu a sua primeira loja no Japão em 1991, após esta lei ter sido emendada. 


\begin{tabular}{|c|c|c|}
\hline \multicolumn{3}{|c|}{ TABELA 4: Japão: leis e políticas para as pequenas e médias empresas (PMEs) } \\
\hline & Leis de Suporte para as PMEs & Leis Financeiras de Suporte \\
\hline 1930 & & $\begin{array}{l}\text { Lei para o Banco Central para as Cooperativas Industriais e } \\
\text { Comerciais, } 1936 \text { (Lei } n^{0} 14 \text { ) }\end{array}$ \\
\hline 1940 & $\begin{array}{l}\text { Lei para Cooperativas para as Pequenas e Médias } \\
\text { Empresas, } 1949 \text { (Lei no 181) }\end{array}$ & $\begin{array}{l}\text { Lei para Cooperativas Financeiras de } \\
\left.\text { de Pessoas, } 1949 \text { (Lei } n^{2} 49\right)\end{array}$ \\
\hline \multirow[t]{4}{*}{1950} & & $\begin{array}{l}\text { Lei de Crédito e Seguro para as Pequenas } \\
\text { e Médias Empresas, } 1950 \text { (Lei no } 264 \text { ) }\end{array}$ \\
\hline & $\begin{array}{l}\text { Lei para a Câmara do Comércio e } \\
\text { Indústria, } 1953 \text { (Lei no 143) }\end{array}$ & $\begin{array}{l}\text { Lei para Corporações Financeiras Japonesas } \\
\text { de Pequeno Porte, } 1953 \text { (Lei no 115) }\end{array}$ \\
\hline & $\begin{array}{l}\text { Lei de Proteção para Atrasos nos Pagamentos de } \\
\left.\text { Subcontratações, } 1956 \text { (Lei } n^{0} 120\right)\end{array}$ & $\begin{array}{l}\text { Lei de Subsídios para Modernização das Pequenas e } \\
\text { Médias Empresas, } 1956 \text { (Lei n } 115 \text { ) }\end{array}$ \\
\hline & $\begin{array}{l}\text { Lei de Medidas Especiais para Acordos com } \\
\text { Varejistas, } 1959 \text { (Lei n 155) }\end{array}$ & \\
\hline \multirow[t]{3}{*}{1960} & $\begin{array}{l}\text { Lei de Promoção para a Modernização das Pequenas } \\
\text { e Médias Empresas, } 1963 \text { (Lei nº 64) }\end{array}$ & $\begin{array}{l}\text { Lei para as Associações de Garantia de Crédito, } \\
1963 \text { (Lei nº 196) }\end{array}$ \\
\hline & $\begin{array}{l}\text { Lei para a Orientaçāo das Pequenas e } \\
\text { Médias Empresas, } 1963 \text { (Lei no 147) }\end{array}$ & \\
\hline & $\begin{array}{l}\text { Lei Básica para as Pequenas e Médias } \\
\text { Empresas, } 1963 \text { (Lei nº 154) }\end{array}$ & \\
\hline \multirow[t]{3}{*}{1970} & $\begin{array}{l}\text { Lei de Promoção para Subcontratações das } \\
\text { Pequenas e Médias Empresas, } 1970 \text { (Lei no 145) }\end{array}$ & \\
\hline & $\begin{array}{l}\text { Lei de Promoção para Varejistas de Pequeno } \\
\text { e Médio Portes, } 1973 \text { (Lei nº 101) }\end{array}$ & \\
\hline & $\begin{array}{l}\text { Lei para Acordos da Atividade Varejista em Relação aos } \\
\left.\text { Estabelecimentos de Grande Porte, } 1973 \text { (Lei } n^{0} 109\right)\end{array}$ & \\
\hline \multirow[t]{2}{*}{1980} & $\begin{array}{l}\text { Lei para Agências de Pequeno e Médio } \\
\text { Portes, } 1980 \text { (Lei n̊ } 53 \text { ) } \\
\text { Lei de Medidas Temporárias para a Promoção } \\
\text { do Desenvolvimento Tecnológico das } \\
\text { Pequenas e Médias Empresas, } 1985 \text { (Lei nº 55) }\end{array}$ & \\
\hline & $\begin{array}{l}\text { Lei de Medidas Temporárias para a Transformação de } \\
\text { Pequenas e Médias Empresas Específicas, } 1986 \text { (Lei nº 4) }\end{array}$ & \\
\hline \multirow[t]{2}{*}{1990} & $\begin{array}{l}\text { Lei para Aperfeiçoamento da Gestão de Empregos } \\
\text { visando a Reservar Força de Trabalho para as } \\
\text { Pequenas e Médias Empresas, } 1991 \text { (Lei n } 57 \text { ) }\end{array}$ & \\
\hline & $\begin{array}{l}\text { Lei de Promoção para Aumentar a Eficiência } \\
\text { das Pequenas e Médias Empresas nas Operações } \\
\text { de Distribuição, } 1992 \text { (Lei nº 65) }\end{array}$ & \\
\hline
\end{tabular}

Desde os anos 80, verifica-se um processo de reestruturação industrial envolvendo as PMEs. Três principais transformações têm ocorrido: escassez de mãode-obra, realização de investimentos no exterior pelas PMEs e ciclos rápidos de inovação tecnológica. Em virtude da composição demográfica do Japão e do aumento do salário real, todas as empre- sas enfrentaram a escassez de mão-deobra, tendo sido forçadas a buscar recursos humanos a custos inferiores.

Como resultado, a imigração ilegal aumentou. As EGPs, assim como as PMEs, prepararam o caminho para a realização de investimentos externos, em razão da carência de mão-de-obra. Esta tendência foi ainda acelerada após 1985, pela valo- 
rização do yen em relação ao dólar. As rápidas mudanças tecnológicas e a diversificação da demanda geraram produtos em maior variedade, mas em menores quantidades. As PMEs tiveram que responder a essas transformações, e, em consonância com estes fatos, algumas leis foram formuladas, de comum acordo com os sindicatos, conforme exposto na tabela 4 .

\section{AS MEDIDAS FINANCEIRAS E FISCAIS}

Existem, no Japão, três instituições financeiras, mantidas pelo governo, voltadas para as PMEs: o Banco Central para Cooperativas Industriais e Comerciais (BCCIC), a Corporação Financeira do Povo (CFP) e a Corporação Financeira para Pequenos Negócios (CFPN). O BCCIC foi estabelecido em 1936, oferece todos os serviços bancários para as PMEs. A CFP, fundada em 1949, é especializada no financiamento das micro e pequenas empresas. A CFPN, constituída em 1953, oferece empréstimos de longo prazo para o financiamento de maquinaria e equipamentos, bem como para capital de giro. A CFP e a CFPN também oferecem empréstimos especiais, sob condições preferenciais, para programas específicos, tais como modernização, antipoluição, conservação de energia e ajustes estruturais. ${ }^{18}$

Para ajudar as PMEs a obter empréstimos dos bancos comerciais, o governo fundou a Associação para a Garantia de Crédito, em 1963. Esta iniciativa decorreu do entendimento de que a pouca credibilidade das PMEs, assim como a ausência de garantias, constituíam os entraves desse processo. A Associação, foi, então, incumbida de garantir os compromissos financeiros, nos casos de empréstimos obtidos junto aos bancos comerciais, o que foi extremamente benéfico. Cinqüenta e duas associações foram estabelecidas por todo o Japāo.

No que se refere aos incentivos fiscais, as PMEs são contempladas com medidas compensatórias, tais como dedução na taxa de cobrança do imposto de renda e no próprio montante desse imposto, concessão de reserva especial e depreciação especial, dependendo dos programas de assistência.

\section{MEDIDAS DE DESENVOLVIMENTO TECNOLÓGICO}

O governo nacional e os locais proporcionam quatro tipos de assistência para as PMEs envolvidas com tecnologia: desenvolvimento dos recursos humanos, orientação e difusão, desenvolvimento tecnológico básico e incentivos para o desenvolvimento tecnológico.

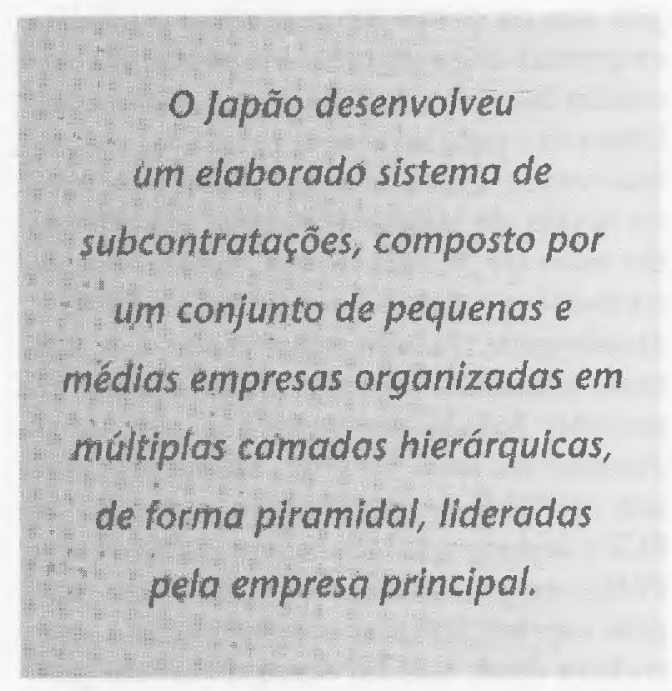

O desenvolvimento dos recursos humanos é apoiado por oito escolas de nível superior, dirigidas pela Agência para as Pequenas e Médias Empresas (APME). Estas escolas proporcionam instrução para o aperfeiçoamento e a especialização dos engenheiros e técnicos, bem como treinamento para os instrutores técnicos das PMEs. Além disso, cada governo jurisdicional possui escolas vocacionais de nível médio. A orientação e a difusão tecnológica são dirigidas por centros de pesquisa públicos e centros locais de demonstração tecnológica; ambos oferecem conhecimentos técnicos especializados e consultoria para as PMEs. Noventa e cinco desses centros fornecem instalações para a realização de testes; em virtude dessa atividade não representar um custo efetivo, as PMEs relutam em adquirir esses equipamentos.

Sessenta institutos nacionais de pesquisa, além da APME, estão envolvidos com pesquisa e desenvolvimento de tecnologia industrial básica. O conhecimento obtido é, desta forma, repassado para as PMEs. Ultimamente, a Lei de Medi-
18. De acordo com o Livro Branco (1991), o montante desembolsado para as PMEs, até 1990, importou em 288.215 biIhões de yens (aproximadamente USS 1.441 bilhōes), do qual essas três instituições (BCGIC CPF e CFPN) contribuiram com apenas $8,6 \% .0$ volume de créditos foi concedido pelos bancos comerciais. As associações de crédito também desempenharam um importante papel, contribuindo com $15 \%$. 
das Temporárias para a Promoção do Desenvolvimento Tecnológico para as PMEs, promulgada em 1985, concedelhes incentivos fiscais e financeiros destinados à pesquisa e ao desenvolvimento de novas tecnologias.

\section{O SISTEMA DE SUBCONTRATAÇõES}

O Japão desenvolveu um elaborado sistema de subcontratações, composto por um conjunto de pequenas e médias empresas organizadas em múltiplas camadas hierárquicas, de forma piramidal, lideradas pela empresa principal. Algumas vezes, esta estrutura alcança até cinco niveis de subcontratações, envolvendo mais de 30 mil firmas. Estes relacionamentos, entre as EGP e as PMEs, atualmente reconhecidos como um dos mais eficientes sistemas de produção do mundo, foram severamente criticados durante os anos 50 e 60 . Denunciava-se um sistema de exploração, no qual as EGPs faziam uso dos baixos salários das PMEs, enquanto acumulavam o seu próprio capital. Este era o argumento da estrutura dual, que foi desaparecendo gradualmente, à medida que a economia japonesa foi conquistando a sua alta taxa de crescimento, consistentemente. Em particular, foi evidenciado que a taxa de lucro sobre o capital era de fato mais elevada nas PMEs do que nas EGPs.

\section{A ESTRUTURA DUAL}

O sistema de subcontratações tem sua origem na experiência de guerra japonesa, ocorrida durante os anos 40 . Com o objetivo de viabilizar a participação das PMEs na produção de armamentos, de forma rápida e eficiente, o governo introduziu o sistema de "fábrica designada", em 1940. De acordo com esse sistema, a empresa principal apresentava um pedido de longo prazo para as subcontratadas indicadas. A assistência técnica era fornecida igualmente. Por outro lado, as subcontratadas designadas eram proibidas de negociar com outras empresas. O sistema não funcionou bem em razão de sua rigidez, mas algumas associações se constituíram, e os keiretsu - a formação de grupos industriais - fermentaram. De acordo com Ueda ${ }^{19}$, muitos exemplos, tais como a Matsushita Electric Co. e a Osaka Metalwork, podem ser pesquisados e descobertos através de uma antiga Lista de Fábricas Associadas de Osaka.

$\mathrm{O}$ debate sobre a estrutura dual no Japão surgiu a partir da coexistência de indústrias modernas e tradicionais, durante os anos 50. As pequenas empresas, que pertenciam principalmente aos setores tradicionais, apresentavam baixa produtividade e baixos salários, com uma tecnologia tradicional e obsoleta, enquanto as grandes empresas já estavam desfrutando de alta produtividade e altos salários, com tecnologia moderna. Existia um gap entre as EGPs e as PMEs e, como resultado, formou-se uma estrutura dual. Os esquerdistas, à época, argumentavam que as EGPs utilizavamse do sistema de subcontratações para explorar as PMEs, através da compressão dos seus lucros. As EGPs tornavamse cada vez maiores pela absorção desta
19. UEDA, $H$. Taiheiyo sensohki ni okeru shitauke-kansei (Relaçōes Subcontratuais durante 0 Período da Segunda Guerra Mundial). Kigyokan Kankel to chushokigyo: chushokigyo riron no saikento (Pequenas indústrias e relaçōes interfirmas: reconsideraçāo da teoria sobre as Pequenas Indústrias). Doyukan, Tóquio: Associaçāo japonesa para as Pequenas e Médias Indústrias, 1992. A Matsushita Eletric Co. tinha 213 subcontratadas, destas 36 foram fábricas designadas em 1943.

TABELA 5: Japão: taxa de lucro de sociedades anônimas na indústria manufatureira

Tamanho por capltal

\begin{tabular}{ccccccc} 
(Milhões de Yens) & $\mathbf{1 9 5 3 - 5 9}$ & $\mathbf{1 9 6 0 - 6 4}$ & $\mathbf{1 9 6 5 - 6 9}$ & $\mathbf{1 9 7 0 - 7 4}$ & $\mathbf{1 9 7 5 - 7 9}$ & $\mathbf{1 9 8 0 - 8 4}$ \\
$2-5$ & 23,5 & 34,0 & 30,1 & 33,3 & 22,3 & 13,4 \\
\hline $5-10$ & 20,4 & 36,0 & 33,1 & 35,2 & 23,7 & 18,2 \\
\hline $10-50$ & 22,4 & 30,7 & 31,8 & 35,3 & 24,2 & 21,4 \\
\hline $50-100$ & 19,2 & 27,2 & 27,6 & 31,1 & 19,1 & 24,5 \\
\hline $100-1000$ & - & 20,9 & 24,7 & 26,2 & 21,5 & 22,8 \\
\hline acima de 1000 & 17,0 & 18,3 & 21,2 & 22,0 & 16,8 & 18,5
\end{tabular}

Fonte: MIWA, Y. Nihon no kigyo to sangyososhiki (Corporaçōes japonesas e estrutura industrial). Japāo: University of Tokyo Press, pg. $15,1990$. 
renda e pela formação de monopólios, enquanto as PMEs eram deixadas para trás.

Este debate desapareceu gradualmente, à medida que a renda cresceu e o pleno emprego foi praticamente atingido. Algumas diferenças salariais permaneceram, ainda, entre empresas de tamanhos diferentes. À medida que as condições macroeconômicas e externas tornaram-se favoráveis para o Japão, as pequenas empresas modernizaram gradualmente a sua estrutura, e o número de empresas médias aumentou. Além disso, intensificou-se a integração das pequenas e médias empresas nos sistemas de produção das empresas de grande porte.

Komiya ${ }^{20}$ alterou a imagem das PMEs ao demonstrar que a taxa de lucro (lucros antes dos impostos, divididos pelo patrimônio líquido) era mais elevada para as PEs do que para as EGPs, em termos do volume de capital. Isto foi também observado por Miwa ${ }^{21}$, conforme exposto na tabela 5 (ver, também, a figura 2). As empresas de maiores dimensões (com capital equivalente ou superior a 1.000 milhão de yens) apresentaram uma taxa de lucro mais baixa, enquanto aquelas de capital de 2 a $50 \mathrm{mi}-$ thões de yens registraram taxas de lucro muito elevadas, de 1960 a 1979 (embora a situação tenha se alterado nos anos 80). Em termos de número de empregados, Kiyonari ${ }^{22}$ identificou uma taxa sem variações para o período de 1961 a 1974, tendo demonstrado que a taxa de lucro sempre foi superior para as empresas com 50 a 299 pessoas, em comparação com as de 300 a 999 pessoas ou acima de 1000 empregados.

Estes fatos demonstram que as PMEs são mais flexíveis, dinâmicas e até mais lucrativas do que se acreditava inicialmente. Isto sugere que o desenvolvimento das PMEs é de vital importância para os países em desenvolvimento.

\section{OS ESTABELECIMENTOS DAS SUBCONTRATADAS}

O número de estabelecimentos de PMEs envolvidos em subcontratações ${ }^{23}$, no setor manufatureiro, alcançou 378 mil em 1987, representando $56 \%$ do total

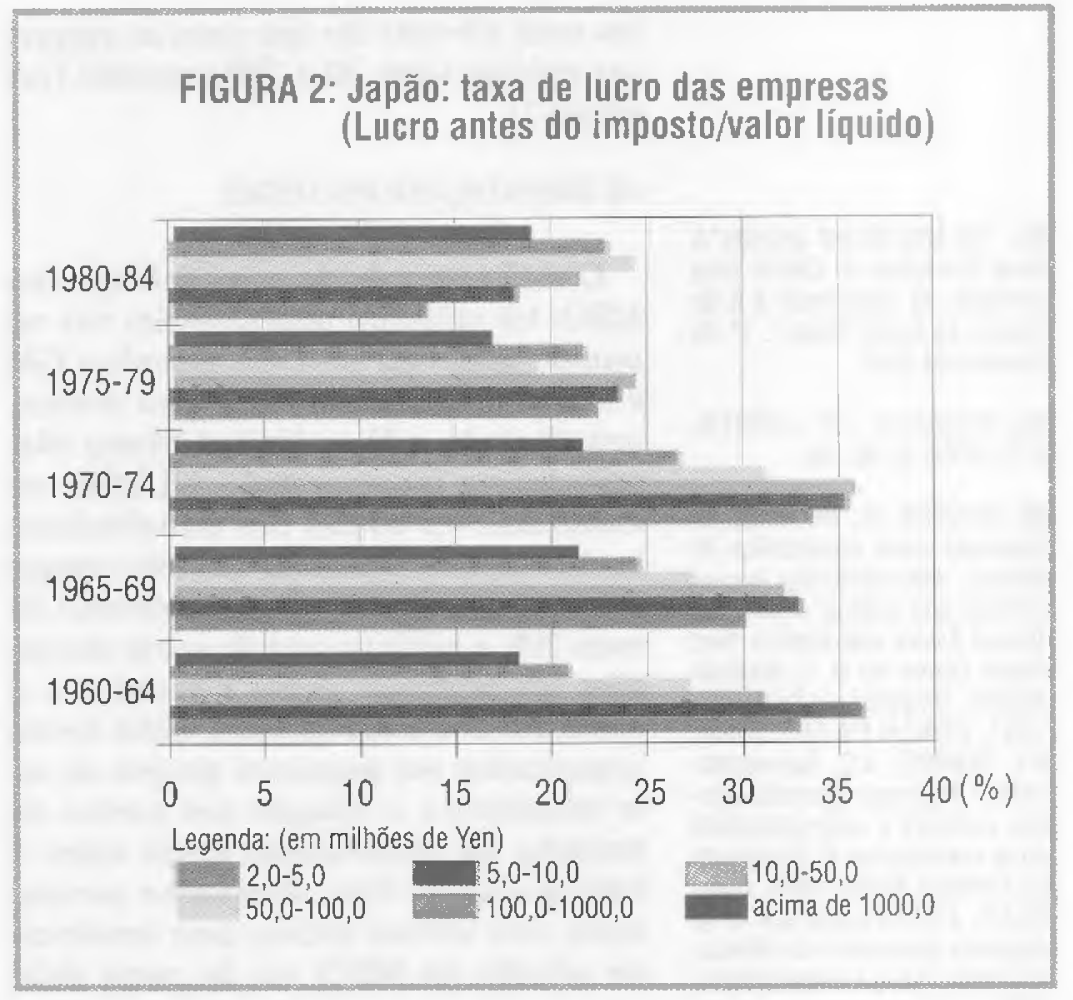

de estabelecimentos observados (ver tabela 6). Para alguns subsetores, tais como maquinaria elétrica $(80,1 \%)$, equipamentos de transporte $(79,9 \%)$, têxteis $(79,7 \%)$, vestuário $(79,0 \%)$, e maquinaria geral $(74,8 \%)$, a prática da subcontratação foi mais freqüente. Geralmentc, os subsetores da indústria leve eram menos envolvidos em subcontratações, exceção feita às indústrias têxteis e de vestuário. Indústrias de bens intermediários, tais como petróleo, produtos químicos e aço, que necessitam de instalações industriais de grande porte, também não apresentavam grandes possibilidades de maiores envolvimentos em subcontratações, em razão da sua própria verticalização interna. As empresas que apresentam maior tendência de envolvimento em subcontratações são as produtoras de bens que requerem muitos processos de produção ou uma infinidade de partes e componentes em sua montagem (ver tabela 6).

Analisando-se o tamanho de uma empresa a partir do número de pessoas envolvidas, quanto menor a empresa, maior a probabilidade de envolvimento em subcontratações. Em 1987, a taxa de subcontratações, para as pequenas empresas (com 1 a 19 pessoas) era 10 pon-
20. KOMIYA, R. Nihon NiokerLs Dokusen to kigyarijun (Manopólio e Lucros Corporativos no Japāo). Kigyokeizai Bunseki. Tóquio: Nakamura, 1962.

21. MIWA, Y. Nihon no Kigyo to sangyososhiki (Corporaçōes japonesas \& estrutura industrial). Japāo: University of Tokyo Press, 1990

22. KIYONARI, T. Chushokigyo Dokuhon (Leituras sobre as Pequenas e Médias Empresas). Tóquio: Toyakeizal Shinposha, 1990.

23. Uma firma subcontratada é uma empresa com 300 lou menos) pessoas envolvidas, ou com capital subscrito equivalente ou inferior a 100 milhōes de yens, que possui uma relaçāo contratual com uma empresa maior (a empresa principal) para fornecimento de uma peça um produto processado ou um material, ou, ainda, envolvida com trabalho de reparo. 
24. The Wall Street Journal,"A Nova Estratégia de Detroit para rechaçar os Japoneses é a de Copiar as Suas Idéias", $1^{2}$ de Outubro de 1992.

25. WOMACK, J.P.; JONES, D.T.; ROSS, D. Op. cit.

26. SHAIEKN, H., BROWNE, H. Japanese work organization in Mexico. Manufacturing across borders and oceans: Japan, the United States and Mexico. San Diego: Center for U. S. Mexican Studies, University of California, 1991; GONZÁLES-ARÉCHIGA, B.Y RAMÍREZ, J.C. Sucontratación y empresas transnacionales: apertura y restructuración en la maquiladora. El Colegio de La Frontera Norte, 1990; CARRILLO, J.V. La nueva era de la industria automotriz en México. El Colégio de la Frontera Norte, 1990. tos mais elevada do que para as empresas médias (com 20 a 299 pessoas) (ver tabela 7).

\section{AS ORIENTAÇÕES POLÍTICAS}

O estilo japonês de administração, ou MEO, foi utilizado pela primeira vez no mundo ocidental em 1983, quando a GM e a Toyota realizaram uma joint venture, constituindo a New United Motor Manufacturing Incorporated - NUMMI, na Califórnia. As tarefas dos trabalhadores horistas foram divididas em três categorias básicas, a partir de um universo de mais 200, e nenhum acordo sobre demissões foi celebrado entre a gerência e o sindicato dos trabalhadores. Estes foram organizados em pequenos grupos de sete membros e a rotação nos postos de trabalho foi introduzida, assim como o Método Just-in-Time. O enorme sucesso desta joint venture iniciou uma tendência de adoção do $\mathrm{MEO}$, ou de parte dele, por outras empresas automobilísticas americanas, tais como a Ford, com o seu modelo Taurus, e, muito recentemente, a Chrysler, com os seus carros $\mathrm{LH}^{24}$. Outras indústrias, como as de aço, eletrônicos e de máquinas de escritório e de precisão, estão aplicando o MEO.

A instalação da Ford na América Latina, em Hermosillo, México, onde foi introduzido o MEO pela Mazda, tornou-se lengendária, tendo sido reconhecida por um estudo realizado pelo MIT em 1990 como a fábrica de automóveis de melhor qualidade em termos mundiais. ${ }^{25}$ Entretanto, outras aplicações do MEO feitas pelas companhias japonesas em diversas indústrias no México, dentre as quais se destacam as "maquiladoras", têm apresentado resultados variados. ${ }^{26}$ Ainda é muito cedo para julgar a aplicabilidade do MEO na América Latina, mas podese destacar que neste momento o MEO é universal, não sendo nem único e nem dependente de sua própria cultura.

Conforme demonstrado pelo exemplo japonês, o papel desempenhado pelo governo é de essencial importância para as PMEs. O mecanismo de mercado e a abertura da economia nacional são, também, necessários, mas mudanças súbitas ou descontinuidades nas políticas previamente implementadas devem ser evitadas. E necessário, também, realizar modificações graduais nas políticas, com orientações claramente definidas.

A experiência japonesa ilustra que as políticas promocionais para as PMEs - assim como os incentivos fiscais e financeiros realizados pelas instituições públicas, são bem efetivos. Entretanto, como a lucratividade das PMEs é mais elevada do que 
se imaginava inicialmente, a proteção deve limitar-se ao seu período de implantação, não devendo ser prolongada.

A ocorrência de um ciclo muito rápido de inovação tecnológica é um fenômeno comum hoje em dia. Considerando-se que o conhecimento tem uma natureza de bem público e requer investimentos maciços, o envolvimento do governo no desenvolvimento de ciência e tecnologia básica é fundamental. E também necessária a existência de um sistema eficiente de difusão, que repasse o conhecimento básico para as PMEs.

Para estabelecer relações produtivas entre as montadoras e os fornecedores, algumas condições são necessárias particularmente no que se refere aos países em desenvolvimento:

a. a menos que existam empresas de partes e de componentes, também chamadas de "indústrias de suporte", não será possível estabelecer um sistema de cadeia de suprimento nestes países. Por meio do investimento estrangeiro direto, as empresas multinacionais trazem consigo as empresas de suporte para os países hóspedes. A criação de PMEs é fundamental. $O$ sistema forma-se gradualmente, à medida que as firmas locais de partes e de componentes se desenvolvem;

b. padronização, uniformidade e sincronização da produção são elementos críticos para a formação de um sistema de subcontratações. Cada parte ou componente deve alcançar o padrão requerido, no que se refere à qualidade, preço, entrega e outros serviços;

c. o compartilhamento da informação é outro fator importante. As estruturas de informações centralizadas devem ser alteradas, e a mentalidade de monopolização das informações deve ser abandonada. O lucro imediato deve ser esquecido. A adoção da atitude de "colocar a qualidade em primeiro lugar", através de cooperação e confiança entre gerentes e trabalhadores, assim como entre as empresas principais e as subcontratadas, produzirá baixos custos e lucros a longo prazo;

d. alguns pré-requisitos solicitados para formar este tipo de sistema industrial incluem estabilidade macroeconômica, infra-estrutura adequada e atuação governamental de suporte. Se a inflação é elevada, por exemplo, $20 \%$ ao mês, os contratos devem ser alterados todo mês. Quando a macroeconomia é instável, o sistema não pode manter os relacionamentos estáveis de longo prazo, necessários para prosperar. Da mesma forma, o sistema depende de uma boa infra-estrutura de transportes e/ou comunicação para funcionar. Por esta razão, o papel do governo é extremamente importante, seja mantendo uma política macroeconômica consistente e investindo em infra-estrutura, seja oferecendo assistência às PMEs, em seu estágio inicial. 